\title{
Harnessing supramolecular peptide nanotechnology in biomedical applications
}

\author{
This article was published in the following Dove Press journal: \\ International Journal of Nanomedicine \\ 9 February 2017 \\ Number of times this article has been viewed
}

\author{
Kiat Hwa Chan' \\ Wei Hao Lee $^{2}$ \\ Shuangmu Zhuo ${ }^{3}$ \\ Ming $\mathrm{Ni}^{3}$ \\ 'Division of Science, Yale-NUS \\ College, Singapore; ${ }^{2}$ Department \\ of Chemistry, Krieger School of \\ Arts \& Sciences, Johns Hopkins \\ University, Baltimore, MD, USA; \\ ${ }^{3}$ Fujian Provincial Key Laboratory \\ for Photonics Technology, Key \\ Laboratory of OptoElectronic \\ Science and Technology for \\ Medicine of Ministry of Education, \\ Fujian Normal University, Fuzhou, \\ People's Republic of China
}

Correspondence: Shuangmu Zhuo; Ming $\mathrm{Ni}$

College of Photonic and Electronic Engineering, Fujian Normal University, Shangsan Road, Cangshan District, Fuzhou City, Fujian Province, 350007, People's Republic of China Email shuangmuzhuo@gmail.com; mingni.sg@gmail.com

\begin{abstract}
The harnessing of peptides in biomedical applications is a recent hot topic. This arises mainly from the general biocompatibility of peptides, as well as from the ease of tunability of peptide structure to engineer desired properties. The ease of progression from laboratory testing to clinical trials is evident from the plethora of examples available. In this review, we compare and contrast how three distinct self-assembled peptide nanostructures possess different functions. We have 1) nanofibrils in biomaterials that can interact with cells, 2) nanoparticles that can traverse the bloodstream to deliver its payload and also be bioimaged, and 3) nanotubes that can serve as cross-membrane conduits and as a template for nanowire formation. Through this review, we aim to illustrate how various peptides, in their various self-assembled nanostructures, possess great promise in a wide range of biomedical applications and what more can be expected.
\end{abstract}

Keywords: peptides, self-assembly, nanotechnology

\section{Introduction}

Peptides are ubiquitous in nature. From the tripeptide glutathione (cellular antioxidant) to oligopeptides (hormones) and polypeptides (proteinaceous enzymes), peptides of various lengths play vital metabolic roles. Unlike these "metabolic" peptides, there are "structural" peptides that need to aggregate or, more specifically, self-assemble into superstructures in order to perform their cellular roles: actin molecules selfassemble to form the elongated fibrillar structures of the cytoskeleton, microtubule molecules self-assemble to form the intracellular transport system, and collagen is an important component of extracellular matrix (ECM) that binds cells and tissues together. These structural peptides possess unique molecular recognition motifs that enable the same peptide molecules to bind together through noncovalent interactions, namely electrostatic interactions, hydrogen bonding, and van der Waals interactions. The elegance of this bioinspired idea that a relatively simple peptide molecule with a unique molecular recognition motif can self-assemble into much more complex and functional superstructures inspires efforts to discover, as well as design, more of such peptides for wide-ranging biomedical applications. ${ }^{1}$

The properties of peptides are extremely tunable due to the variety of basic building blocks, ie, amino acids, available. Three features of amino acids contribute to the wide variation in the properties of peptides: 1) the different categories of amino acid side chains, ie, polar and nonpolar (eg, Asn, Ser vs Leu, Val), acidic and basic (eg, Asp, Glu vs Lys, Arg), and aromatic and aliphatic (eg, Phe, Trp vs Ile, Ala), contribute different and varying degrees of intermolecular interactions. This feature has been extensively exploited in the design of artificial proteins, in which hydrophobic residues 
form the internal four-helix bundles, whereas hydrophilic residues line the exterior; ${ }^{2} 2$ ) the two different chiral forms of amino acids, ie, L (natural) and D (unnatural) forms, have different effects on the secondary structures formed by the oligopeptides and are readily accessible; the latter advantage is very desirable as oppositely chiral building blocks are often not readily accessible and consequently costly. Chirality, together with the aversion of nonpolar residues to water (manifested in the periodicity of nonpolar/polar residues) $)^{3}$ and, to a lesser extent, the propensity of different amino acid residues to favor different secondary structures (eg, $\alpha$-helix and $\beta$-sheet), contributes to the secondary and higher order structures adopted by the vast majority of biological polypeptides; 3 ) there are amino acids with side chains (eg, Ser, Cys, Glu, and Lys) that permit the attachment of desired molecules, which may be a fluorophore, a metal-binding ligand, or even a nanoparticle., ${ }^{4,5}$ This is analogous to how biological systems utilize phosphorylation or sulfation of Ser or Tyr to modify the biological properties of various proteins. Evidently, these three factors provide a vast combinatorial space for the design and tuning of selfassembling peptides. ${ }^{6}$

Peptides are naturally suited to biomedical applications because of their general biocompatibility with the human body (despite a small number of exceptions, eg, peptidic neurotoxins). For instance, many peptides such as ecallantide and liraglutide have been utilized as therapeutics for the treatment of myriad human conditions. ${ }^{7-10}$ As nanomedicines, these peptides exert their therapeutic functions as single molecules. However, there are also peptides that are known to exhibit therapeutic functions through self-assembled nanostructures. Such peptides self-assemble into the following three major classes of nanostructures: 1) long nanofibrils with solid cores, 2) spherical nanoparticles, and 3) long nanotubes with hollow cores. It is even possible for certain peptides to adopt different nanostructures by controlling the surrounding pH. ${ }^{11}$ Naturally, by virtue of their different shapes, they can be applied in different functional contexts. In the following sections, we explore how different peptide nanostructures can potentially be applied in various biomedical settings. In the section Peptide nanofibrils as tissue scaffolds, we explore how peptides that self-assemble into long nanofibrillar structures have the ability to entrap water to form hydrogels, which in turn are able to serve as three-dimensional scaffold materials to support the growth of various tissues in the area of tissue engineering. We explore the applications of peptide hydrogels in the following three critical areas: bone/cartilage engineering, neural tissue engineering, and angiogenesis. In the section Peptide nanoparticles as drug delivery agents and bioimaging probes, we explore how some peptides can self-assemble into nanoparticles that enclose drugs and vaccines. This application works on the basis of the small size of the nanoparticles, which permit their facile entry into cells. (There is the related field of adorning nonpeptidic nanoparticles with antigenic peptides to facilitate their uptake into target cells, such as cancer cells and bacteria, but this will not be covered in the current review.) In the section Peptide nanotubes in cross-membrane applications, we explore peptides that can self-assemble long tubular structures, which in turn permit them to serve as nanotubes for crossmembrane applications. These three self-assembled peptide nanostructures and their associated biomedical applications are succinctly summarized in Figure 1.

\section{Peptides}

\section{Peptide nanofibrils as tissue scaffolds}

The cherished goal in tissue engineering is to be able to replace a significant amount of damaged tissue with healthy tissue that is cultivated ex vivo. This in turn would require a synthetic biomaterial that resembles the native tissue so that the target cells that are seeded in the biomaterial can proliferate successfully to reconstitute the desired tissue. ${ }^{12}$ A hydrogel can serve as an ideal tissue engineering biomaterial because it is composed largely of water and provide a three-dimensional environment for cellular proliferation. There are many excellent synthetic materials that have been explored as tissue engineering substrates, such as polylactic acid (PLA), polyglycolic acid (PGA), and poly(lactic-coglycolic acid) (PLGA). Although these polymeric materials are biodegradable, their degradation is slow, ${ }^{13}$ and it means that it will take a much longer time for the body to assimilate the newly reconstituted tissue. In addition, the hydrophobicity of these polymers could elicit immune responses that lead to the degradation of the new tissue or even the original healthy tissue. ${ }^{14}$ Due to these concerns, there are efforts to explore naturally derived biomaterials (eg, agarose and collagen) as tissue engineering substrates. Collagen is an especially attractive substrate because it is the major component of natural ECM. However, while agarose is derived from algae, collagen is extracted from animal sources, and this limits its acceptance as a tissue engineering substrate due to public concerns with viral contamination. Thus, in order to tap into the tissue engineering potential of collagen, which is a polypeptide, one way is to turn to synthetic peptides instead.

Currently, peptides are readily synthesized through a number of methods: recombinant peptide production in microbial expression platforms ${ }^{15}$ and chemical ligation 
A

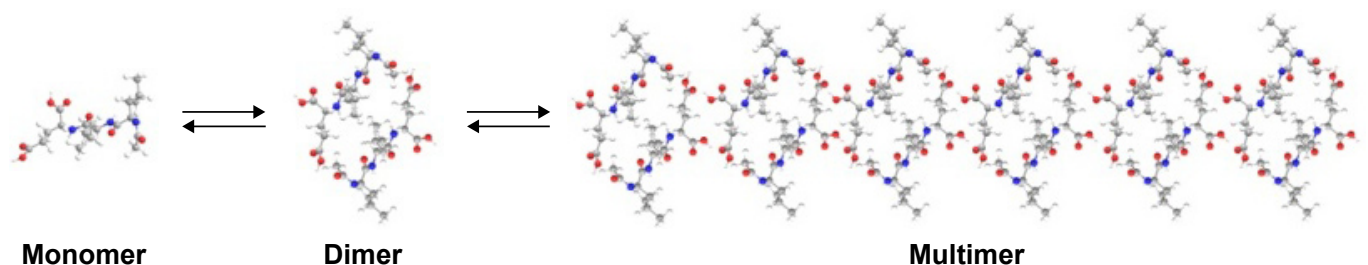

Monomer

Dimer

Multimer

Potential applications of self-assembled supramolecular structures

B

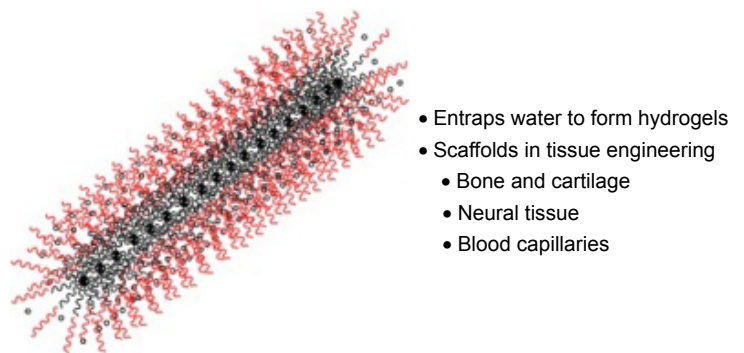

Nanofibrils

C

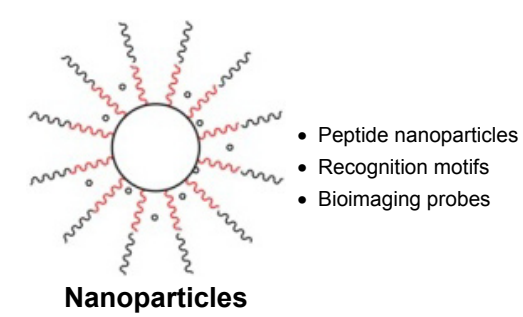

\section{Nanopores}

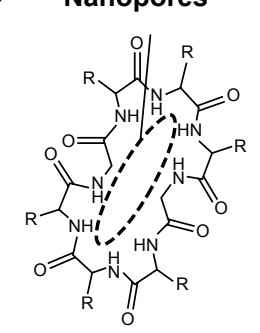

Top view

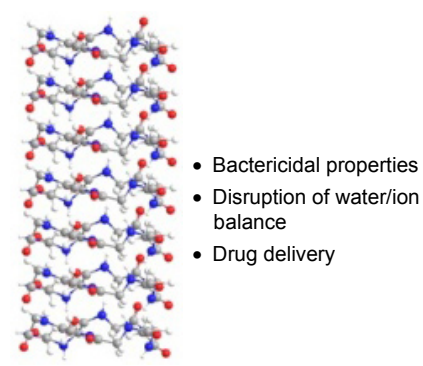

Side view

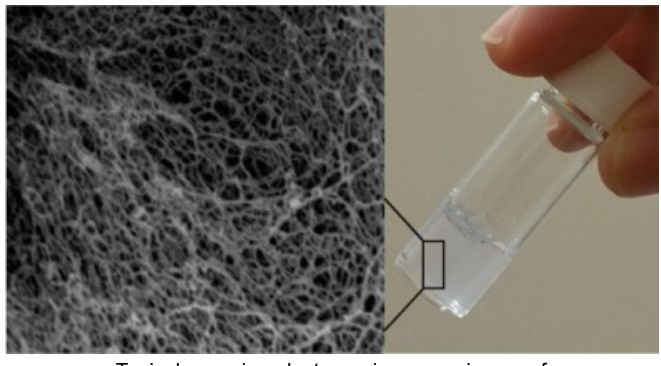

Typical scanning electron microscopy image of hydrogel (15,000× magnification)

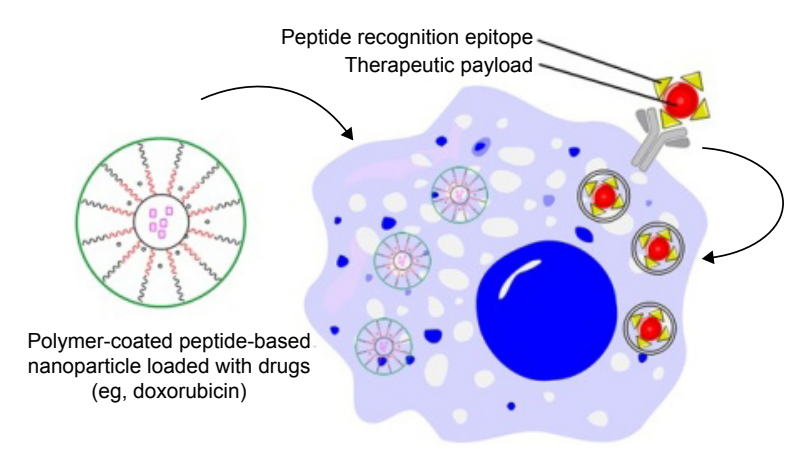

Nanotubes

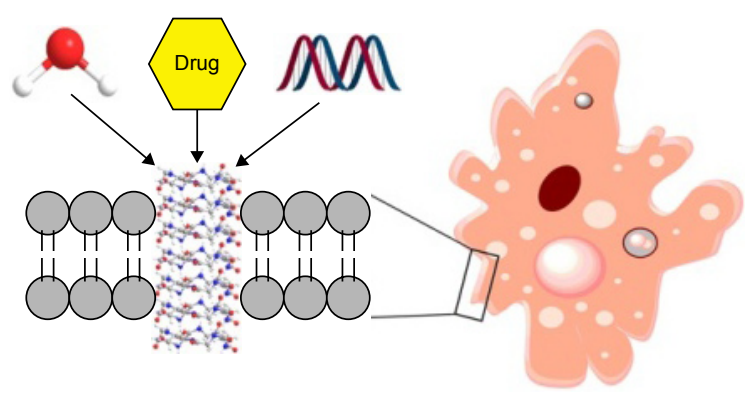

Figure I Illustration of self-assembly of peptides and the possible applications of three different nanostructures.

Notes: (A) Peptides can undergo self-assembly to form supramolecular multimers. (B) Nanofibrils entrap water to form the hydrogel. (C) Nanoparticles function as a vehicle to transport various molecules into the cell. (D) Nanotubes can span the cell membrane and allow various molecules to translocate in/out of the cell. The scanning electron microscopy image was adapted from Gelain F, Bottai D, Vescovi A, Zhang S. Designer self-assembling peptide nanofiber scaffolds for adult mouse neural stem cell 3-dimensional cultures. PLoS One. 2006; I:el 19. Creative Commons license and disclaimer available from: http://creativecommons.org/licenses/by/4.0/legalcode. ${ }^{56}$

are used for polypeptides, whereas solid-phase peptide synthesis can be utilized for oligopeptides. Although it is technically possible to produce collagen synthetically, it is challenging and costly to purify large quantities of collagen for tissue engineering purposes. However, it is relatively easy to purify oligopeptides and can be cost-efficient to produce them on a large enough scale to meet the demands of biomedical needs. ${ }^{16}$ The discovery that oligopeptides can also self-assemble through noncovalent interactions into higher order structures resembling those of collagen opens up the exciting possibility of utilizing oligopeptides as tissue engineering substrates. Indeed, many oligopeptides have been reported to be capable of forming hydrogels, which is the desired basis for tissue engineering as discussed. It has been widely observed that the oligopeptides self-assemble into long nanofibers to form an extensive network of fibrils that entrap water to establish the physical form of the hydrogel. Due to the noncovalent interactions among the 
oligopeptides, it is possible for the fibrillar network to be resorbable and allows the new tissue to be fully assimilated with the original tissue. Thus, the ease of production/purification of oligopeptides and the resorbability of peptide hydrogels are two important features that make oligopeptides suitable tissue engineering substrates.

The large volume of water ( $>80 \%$ by mass) of a hydrogel translates into space within which cells can inhabit. As a mammalian cell is very large $(\sim 10 \mu \mathrm{m})$ compared to the width of the peptide nanofiber $(\sim 0.05-0.10 \mu \mathrm{m})$, the cells are really suspended in water and come into only limited contact with the peptide nanofibrils (Figure 1A). In order to form a tissue, the cells have to be spatially aligned with respect to each other - for instance, the long axes of the striated muscle cells have to be aligned parallel to each other in order to produce traction. In addition, cells can sense mechanical strains through the cellular membranes and this can affect cellular metabolism drastically. ${ }^{17}$ In order to control these two aspects, this means that the cells have to be spatially immobilized. To achieve this, what is commonly attempted is to adorn the nanofibrils with cellular recognition motifs that can 1) adhere cells to the nanofibrils and assist in cell-to-cell alignment and 2) in the case of seeded stem cells, help to direct the differentiation fate. ${ }^{18,19}$ Naturally, depending on the tissue type, different cellular recognition motifs are required. In the following sections, we explore how different tissues can be grown using various peptide hydrogels.

\section{Bone and cartilage tissue engineering}

Bone and cartilage together make up the physical support structure of the human body. While small children and young adults can recover fairly easily from minor fractures and bone injuries, the elderly will take a much longer time to recuperate, thus reducing mobility and quality of life. Similarly, people who suffer severe impact injuries through work, sports, or accidents suffer both physically and economically. The same ramifications apply to patients with cartilage damage. Being the cushion material between the bone joints, cartilage serves the critical function of smooth joint mobility. Due to advancing age or arthritis, cartilage can be worn out to the extent that ordinary joint motion is accompanied by excruciating pain and discomfort. This is especially acute in the case of degenerative disk disease of the intervertebral disk. Thus, there is naturally a need for expeditious bone repair and cartilage replacement so that the patient can resume normal life as soon as possible.

For patients with serious bone/cartilage damage and requiring bone/cartilage replacement, autografts and allografts are currently the choice of bone/cartilage replacement materials, despite their inherent limitations. ${ }^{20,21}$ Although relatively minor bone injuries such as fractures can be sealed with bioglass and bone cement, ${ }^{22}$ native bone tissue will not be able to self-repair future damage to the same locality; the regeneration of cartilage upon wear and tear is very limited as it is avascular. ${ }^{23}$ An approach that can cater to both major and minor injuries is to provide a conducive environment around the injury site in which native osteoblasts (bone) $)^{24,25}$ and chondroblasts (cartilage) $)^{26,27}$ can take root and regenerate new tissue faster. This would involve either 1) the native recruitment of bone marrow-derived progenitors, ie, bone marrow stromal cells (BMSCs), ${ }^{28}$ as osteoblast and chondroblast precursors to the injury site, or 2) the exogenous transplantation of BMSCs to the injury site pending induced differentiation into osteocytes or chondrocytes.

Many biomaterials have been explored as three-dimensional scaffolds for bone and cartilage regeneration. ${ }^{29-31}$ From these studies, it has been learned that the surfaces of the biomaterials have to be conducive for the attachment and proliferation of the relevant cell types. ${ }^{32}$ In this regard, peptide hydrogels are eminently suited as molecular scaffolds ${ }^{33}$ for bone and cartilage regeneration for the reasons outlined in the "Introduction" section. Besides being functionalizable with epitopes that promote BMSC attachment when prominently presented to the microenvironment, the nanoporous peptide scaffolds also permit the unrestricted diffusion of growth factors and various cellular signals to promote the regenerative process. ${ }^{34,35}$ This is prominently illustrated by the study of Horii et al, ${ }^{36}$ in which various short peptide sequences, ie, DGR, ALK, and PGR, tacked onto the hexadecapeptide [(Arg-Ala-Asp-Ala) ${ }_{4}$ or RADA16-1] hydrogel, respectively, promoted the adsorption, proliferation, and migration of osteoblasts within the RADA16-1 hydrogel (Figure 2). As shown in Figure 2, the backbone of RADA16-1 self-assembles in a $\beta$-sheet configuration, thus displaying the various epitopes in an orderly fashion for them to serve their functions. A similar $\beta$-sheet assembly of peptides, but comprising aspartic amino acids, is able to bind calcium ions to further enhance the ability of the peptide hydrogel (compared to an absence of calcium) to promote osteogenesis. ${ }^{37}$ In fact, it has been demonstrated that it is even possible to combine motifs with different functions, eg, Arg-Gly-Asp (RGD) as a cell adhesion motif and phosphoryl serine as a calcium binder, on the same peptide molecule to synergize osteogenesis (Figure 3). ${ }^{38,39}$

Similarly, peptide hydrogels have been shown to be capable for promoting chondrogenesis. ${ }^{40}$ The hydrogels of RADA16-1 and (Lys-Leu-Asp-Leu) (KLDL16-1), a functional analog of RADA16-1 (Arg $\rightarrow$ Lys; Ala $\rightarrow$ Leu), 


\begin{tabular}{|c|c|c|}
\hline Name & Sequences & Description \\
\hline RADA16 & $\mathrm{Ac}(\mathrm{RADA})_{4} \mathrm{CONH}_{2}$ & Designed \\
\hline ALK & $\mathrm{Ac}(\mathrm{RADA})_{4} \mathrm{GGALKRQGRTLYGF-CONH_{2 }}$ & $\begin{array}{l}\text { From osteogenic growth } \\
\text { peptide }\end{array}$ \\
\hline DGR & $\mathrm{Ac}(\mathrm{RADA})_{4} \mathrm{GGDGRGDSVAYG-CONH}{ }_{2}$ & $\begin{array}{l}\text { From cell adhesion } \\
\text { domain (osteopontin) }\end{array}$ \\
\hline PRG & $\mathrm{Ac}(\mathrm{RADA})_{4}$ GPRGDSGYRGDS-CONH ${ }_{2}$ & 2-unit RGD motifs \\
\hline
\end{tabular}

B

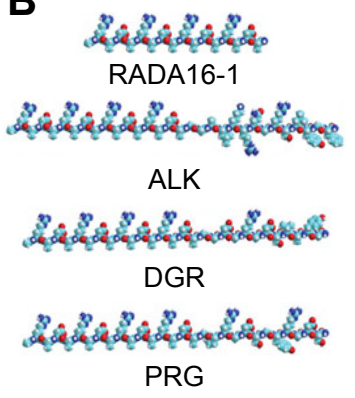

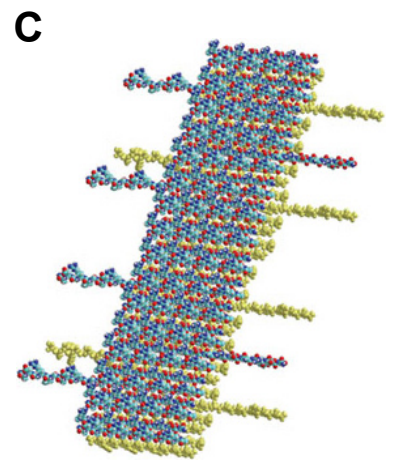

Figure 2 Functionalization of RADAI6 with various bioactive peptide motifs.

Notes: (A) Functionalization of RADAI6 with various bioactive peptide motifs. (B) Molecular structures of RADA I6, ALK, DGR, and PRG. (C) Proposed self-assembly of RADA I 6 backbone to expose bioactive peptide motifs along the flanks of the $\beta$-sheet. The image is adapted from Horii A, Wang X, Gelain F, Zhang S. Biological designer selfassembling peptide nanofiber scaffolds significantly enhance osteoblast proliferation, differentiation and 3-D migration. PLoS One. 2007;2(2):el90. Creative Commons license and disclaimer available from: http://creativecommons.org/licenses/by/4.0/legalcode. ${ }^{36}$ The sequences are from $\mathrm{N}->\mathrm{C}$. Ac $=$ acetylated $\mathrm{N}-$ termini, $-\mathrm{CONH} \mathrm{H}_{2}=$ amidated C-termini. The peptide motif sources from various protein origins. The 2-unit RGD motifs are purely molecular designed.

are capable of maintaining the phenotype of differentiated chondrocytes and promote chondrogenesis both ex vivo and in vivo..$^{41,42}$ In the study of Miller et al, ${ }^{42}$ they compared the effect of chondrogenic factors ( $\mathrm{CFs})$ and BMSCs on the ability of KLDL16-1 hydrogels to promote chondrogenesis in a rabbit cartilage defect model. Intriguingly, KLDL16-1 hydrogels without any BMSCs or CFs were observed to improve cartilage repair the most; this is in contrast to previous observations in which CFs in gelatin sponges improved cartilage repair. ${ }^{43-45}$ Various functional moieties that promote chondrogenesis have also been attached to peptide hydrogels. A multidomain peptide similar to that designed by Hartgerink et al, ${ }^{38}$ but one which possesses a sulfate functional group, has been found to be capable of supporting the chondrogenic differentiation of rat mesenchymal stem cells; ${ }^{46}$ presumably, the sulfated moiety acts like native sulfated glycosaminoglycan in attracting growth factors that facilitate chondrogenic differentiation. Another multidomain peptide, which includes His-Ser-Asn-Gly-Leu-Pro-Leu as a binding motif for transforming growth factor beta-1 (TGF $\beta-1$ ), facilitates chondrogenic differentiation of human mesenchymal stem cells by releasing TGF $\beta-1$ in a controlled manner. ${ }^{47}$
The link N peptide, which can stimulate the biosynthesis of collagen II (a major component of cartilage) by cells of the intervertebral disk, ${ }^{48,49}$ has been incorporated into peptide hydrogels to promote nucleus pulposus regeneration ${ }^{50,51}$ as well as chondrogenesis of rabbit BMSCs. ${ }^{52}$ These results represent very promising prospects to alleviating what has thus far been an intractable medical problem.

\section{Neural tissue engineering}

Neural tissue repair is currently one of the important medical targets. Unlike damage to the nerves of the peripheral nervous system (PNS), which can be repaired through suturing, ${ }^{53}$ damage to the central nervous system (CNS) can only be repaired to a limited extent with current medical technology. The impact of even small advancements in spinal cord repair is obvious: the amelioration of spinal cord damage-inflicted paralysis would mean a tremendous improvement in the quality of life and restoration of self-esteem to millions of patients. ${ }^{54}$ It means that the patients could return to normal lives of independence and gainful employment, thus enormously reducing the emotional and financial burdens on their families and friends.

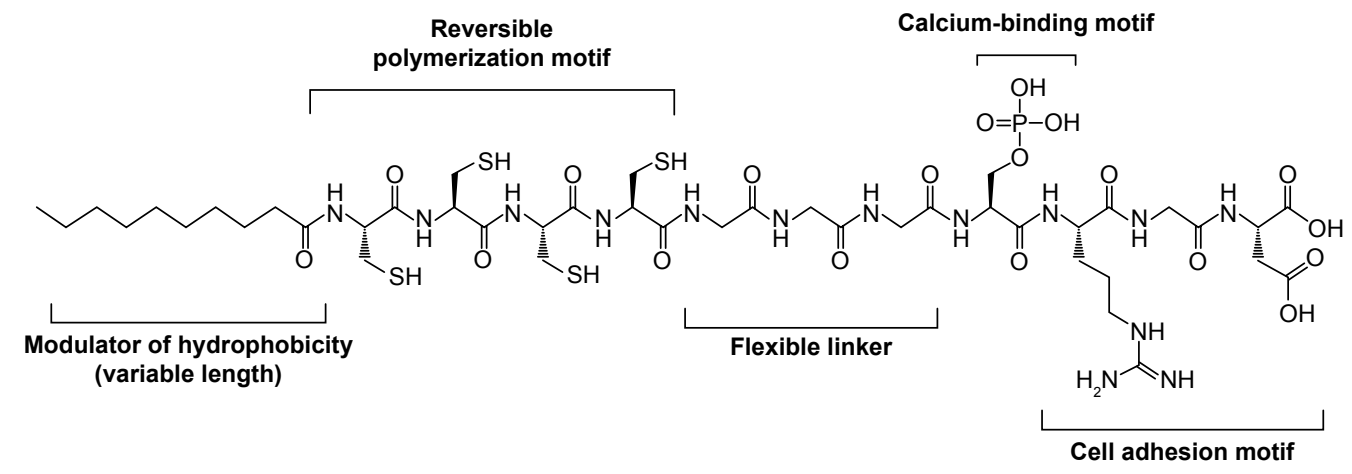

Figure 3 Example of multidomain peptide molecule. 
While the PNS is able to self-repair through axonal regrowth, this process is inhibited in the CNS. One of the impediments to axonal regrowth is the formation of glial scars at the injury site, ${ }^{55}$ which in turn has been partially attributed to the absence of laminin in the ECM. Naturally, one way forward for tissue engineering is to employ hydrogels that are decorated with laminin-derived sequences in hope that the glial scar formation can at least be partially averted. As Gelain et al have shown, ${ }^{56}$ even the basic RADA16-1 hydrogel is capable of supporting the proliferation of (murine) neural stem cells (NSCs). Decoration of similar peptide nanofibrils with the fibronectin-derived sequence RGD ${ }^{57}$ have been reported to be able to improve the proliferation of murine NSCs over the undecorated peptide nanofibers. ${ }^{58}$ Thus, perhaps unsurprisingly, when the RADA16-1 nanofibers were decorated with the laminin-derived sequence Ile-Lys-Val-Ala-Val (IKVAV), ${ }^{59}$ the hydrogel not only improved tissue regeneration but also supported the proliferation of NSCs in a rat brain surgery model up to 6 weeks posttransplantation. ${ }^{60}$ Very importantly, this IKVAV-decorated RADA16-1 hydrogel was indeed able to reduce glial scar formation. The key indicator of the efficaciousness of the peptide hydrogel, however, is the ability of the hydrogel to promote resection of a transected rat spinal cord with a gap of $>4 \mathrm{~mm}$. In this regard, even PuraMatrix ${ }^{\circledR}$ (ie, RADA16-1) passes the transection-resection criterion with flying colors. ${ }^{61}$ Thus, the IKVAV-decorated RADA16-1 hydrogel can be expected to be even more effective at promoting axonal regrowth of the CNS.

\section{Angiogenesis}

The growth of bone, cartilage, nerves, or any other tissues necessitates the concomitant development of new microvasculature, ie, angiogenesis, within the new tissue. Angiogenesis is an extremely important process as the blood capillaries are the conduits through which oxygen and nutrients are delivered to, and metabolic waste products are transported away from, the newly developing tissues. This is especially critical in cases that use stem cells to regenerate the desired tissue as the differentiation fates of stem cells are intimately linked to the cell culture medium. Thus, herein lies a challenge: how can the tissue engineering substrate provide a three-dimensional environment that can promote the growth of the desired tissue and blood capillaries simultaneously?

Peptide hydrogels can contribute to angiogenesis by serving as the delivery agent of therapeutic factors such as basic fibroblast growth factor and vascular endothelial growth factor (VEGF). This can be achieved through the entrapment of the therapeutic factors within the hydrogel, ${ }^{62,63}$ or the covalent immobilization of the factors to the hydrogel matrix; ${ }^{64}$ for the latter strategy, the therapeutic payload would be released upon cellular degradation of the factor-matrix linkages. Alternatively, hydrogels can serve as the structural scaffold for angiogenesis, in which the three-dimensional matrix and the angiogenic functional motifs decorating the peptide nanofibers synergize to provide superior conditions for angiogenesis. As Liu et $\mathrm{a}^{65}$ have shown, when the two functional motifs (fibronectin-derived PRGDSGYRGDS and VEGF-mimic KLTWQELYQLKYKGI) were attached to RADA16-1, the resultant hybrid peptide hydrogels exhibited superior angiogenic activities compared to the parent RADA16-1 hydrogel. Another multidomain peptide, ie, $\mathrm{KK}(\mathrm{SL})_{7} \mathrm{KK}$, has also been tested along with the following three other analogs: 1) $\mathrm{K}(\mathrm{SL})_{2} \mathrm{~S} L R G(\mathrm{SL})_{3} \mathrm{~K}$ that possesses an enzyme cleavage site, 2) $\mathrm{K}(\mathrm{SL})_{2} \mathrm{~S} L R G(\mathrm{SL})_{3} \mathrm{KGR} G D S$ that possesses both an enzyme cleavage site and a cell adhesion motif, and 3) K(SL) 2 SLRG(SL) KGKLTWQELYQLKY KGI that possesses both an enzyme cleavage site and the VEGF mimic. ${ }^{66}$ The cleavage enzyme site was incorporated as a way for the body to gradually break down the hydrogel so that new tissue can take the place of the hydrogel. Unsurprisingly, multidomain peptide decorated with the VEGF mimic promoted angiogenesis to the greatest extent. It is also noteworthy that when VEGF mimic was not covalently attached to the peptide nanofiber, the angiogenic activity was significantly poorer. Thus, multidomain peptides certainly have a lot of potential in promoting angiogenesis.

\section{Peptide nanoparticles as drug delivery agents and bioimaging probes}

Peptides are able to form nanoparticles (particulate size $<100 \mathrm{~nm}$ ) depending on the sequence and solvent conditions. A prominent example is (tert-butoxycarbonyl) diphenylalanine (Boc-Phe-Phe). Despite being only a dipeptide, Boc-Phe-Phe is able to self-assemble either into nanoparticles or into nanotubes depending on the solvent conditions ${ }^{67}$ This is analogous to the self-assembly of some proteins, eg, the man-made spider silk protein, eADF4(C16), which forms microspheres at high concentrations of potassium phosphate $(>400 \mathrm{mM})$ but forms nanofibers at low concentrations of potassium phosphate $(<300 \mathrm{mM}){ }^{68}$ A common feature of the peptides that form nanoparticles is the presence of aromatic amino acid residues in their sequences, eg, Phe-Tyr, ${ }^{69}$ Phe-Phe-Phe, ${ }^{70}$ and various Trpbased oligopeptides derived from the truncation of gramicidin A. ${ }^{71,72}$ Presumably, self-assembly of the peptides is facilitated 
through $\pi-\pi$ stacking of the aromatic residues. ${ }^{73,74}$ Interestingly, the nanoparticles formed by truncated Trp-peptides of gramicidin A are able to further assemble into higher order peptide beads, ${ }^{71}$ in a manner analogous to proteins such as $\beta$-lactoglobulin ${ }^{75}$ and apo- $\alpha$-lactalbumin/lysozyme. ${ }^{76}$ This makes possible the simultaneous delivery of multiple drugs by compartmentalizing different drugs within a peptide bead. ${ }^{71,72}$

The following three features of peptide nanoparticles lend themselves well to drug delivery: 1) the small size of nanoparticles $(<100 \mathrm{~nm})$ enables them to permeate the target cells of interest, ${ }^{77} 2$ ) the peptides can be designed to interact with the drug but still can self-assemble and encapsulate the drugs within the core of nanoparticles, ${ }^{78}$ and 3) the surface of the nanoparticles can be adorned with cell recognition motifs. ${ }^{79,80}$ For example, doxorubicin, a nonpolar anticancer drug, has been loaded inside dendrimeric peptide nanoparticles. These nanoparticles have been decorated with peptide epitopes of cathepsin B (which are abundant on cancer cells), enabling them to target cancerous cells more effectively (Figure 1B) ${ }^{81}$ To integrate and capitalize on the abovementioned features more effectively, Raman et al have used computer modeling to design self-assembling peptide nanoparticles (SAPNs) ${ }^{82}$ As a result, SAPNs as small as $16 \mathrm{~nm}$ can be designed. Allowance can thus be made to present epitopes on the surface of the SAPNs, which in turn equip the SAPNs to home in on their targets. In this manner, SAPNs have been successfully explored as vaccines for various infectious diseases, such as $\mathrm{HIV},{ }^{83}$ influenza, ${ }^{84}$ and malaria.$^{85}$ In the case of the SAPNbased malarial vaccine, it has been found to immunize mice for up to 6 months after the first parasite challenge, and up to 15 months after the second parasite challenge. ${ }^{85}$ The success of SAPN-based malarial vaccines in mice has prompted the assessment of these vaccines in human clinical trials, which can be expected to proceed in $2017 .{ }^{86}$

In addition to drug/vaccine delivery, peptide nanoparticles have been reported to possess remarkable optical properties, rendering them suitable as bioimaging probes. Flt1 peptide-based nanoparticles, which contain only one tryptophan (W) and one phenylalanine (F) per peptide as chromophores, can be bioimaged through two-photon microscopy. ${ }^{87,88}$ Along with triphenylalanine (FFF) nanobelts and diphenylalanine (FF) nanotubes, FFF nanoparticles have been reported to exhibit second harmonic generation (SHG) effect; ${ }^{70}$ as a result, the FFF nanoparticles can convert near infrared (NIR) light to green or blue light. This property renders FFF nanoparticles suitable as bioimaging probes as NIR light can penetrate tissue more deeply, thus permitting real-time deep tissue bioimaging. As the nanoparticles are formed through noncovalent self-assembly, these nanostructures may change form over time and alter their properties. Fan et $\mathrm{al}^{69}$ have reported that it is possible to stabilize the structure of tryptophan-phenylalanine nanoparticles with zinc(II) ions, which leads to nanoparticles that are more photostable and superior optical properties (ie, narrow emission bandwidth in the visible spectrum). Incidentally, these fluorescent nanoparticles can also be functionalized with the MUC1 aptamer (MUC is overexpressed in some cancers) and loaded with doxorubicin (an anticancer drug), making these multifunctional nanoparticles an ideal theranostic agent, namely the progress in which these multifunctional nanoparticles target cancer cells and deliver their payload that can be monitored in real time.

\section{Peptide nanotubes in cross-membrane applications}

A cyclic peptide is an oligopeptide in which the $\mathrm{N}$ and $\mathrm{C}$ termini of a linear peptide are linked together to form a cyclic structure. Cyclic peptides discovered in nature have found many uses in medicine: vancomycin is a very important antibiotic that is used only when first-line antibiotics are not effective; cyclosporine is an immunosuppressant that is prescribed to a patient of organ transplantation to facilitate the acceptance of the new organ; and octreotide is a pharmacological mimic of somatostatin that is utilized to alleviate the symptoms of certain carcinoid tumors. While the pharmacological efficacies of these applications may or may not depend on the cyclic structure of the peptide, there is one application in which this structural characteristic is critical: the formation of peptide nanotubes. ${ }^{89}$

Peptide nanotubes are formed from the stacking of multiple cyclic peptides (mostly synthetic) on top of each other into a tubular structure; the stacked cyclic peptides enclose an empty space of a few nanometers wide, depending on the size of the cyclic peptide. ${ }^{90}$ Not all cyclic peptides are able to self-assemble into nanotubes. In general, cyclic peptides with an even number of amino acid residues and relatively small number of residues $(\leq 14)$ self-assemble into more stable nanotubes: when the cyclic peptide possesses an odd number of amino acid residues, the structure is not flat and, consequently, not conducive for stacking; when the cyclic peptide is too big, it is structurally more "floppy" and the exact conformation required for stacking is much harder to attain. ${ }^{91}$ In addition, the amino acid residues in the cyclic arrangement have to be alternating in L (natural) and D (unnatural) forms in order to minimize steric clashing 
between the amino acid side chains of two stacked peptides and maximize interpeptide hydrogen bonding..$^{92}$ These three stringent requirements have led to the development of peptide nanotubes ${ }^{93}$ that are stable enough to permit the translocation of water through them in a similar way that aquaporins translocate water across cell membranes. ${ }^{94}$

The ability of these synthetic peptide nanotubes to translocate water makes it possible to adapt them for therapeutic purposes. ${ }^{95-98}$ The key idea is that these cyclic peptides could be adorned with cell recognition motifs that target cancerous cells or bacteria. Upon encountering the target cell, the cyclic peptides can permeate the cell membrane and self-assemble to form nanotubes across the membrane (Figure 1C). ${ }^{99}$ Through the artificial channel, water can translocate into the target cell and effect cytolysis, killing the cell. With suitable modifications to the peptides, it can be possible to modulate the peptide nanotubes to translocate ions, ${ }^{100,101}$ so anticancer or bactericidal effect can be achieved through disrupting the salt balance of the target cells. Hydrophilic drugs can also be contained with the hydrophilic peptide nanotube interior ${ }^{102,103}$ and be transported into the target cells. This is a common problem with many hydrophilic drugs, in that they are unable to cross the hydrophobic cell membrane. ${ }^{104}$ However, there have not been significant reports of the use of peptide nanotubes as described. This could be due to the limitation of requiring significant concentration of the cyclic peptides in a locality in order for self-assembly to proceed; massive dilution occurs upon injection into the bloodstream. Hence, there is a need to develop efficient strategies to overcome this dilution issue before the nanotechnological applications can be realized. One way may be to utilize carbon nanotubes ${ }^{105}$ or block copolymers ${ }^{106}$ to "concentrate" the cyclic peptides in order to favor their nanotube formation.
Nanotubes can also be formed through, specifically diphenylalanine, either dilution of a high concentration of diphenylalanine in hexafluoro-2-propanol into water ${ }^{107}$ or vapor deposition methods. ${ }^{108}$ Unlike the cyclic peptides that enclose nanopores by virtue of their molecular structures, 12 diphenylalanine molecules first self-assemble to enclose a nanopore. In turn, the diphenylalanine molecules form a fibril with $110 \mathrm{~nm}$ outer diameter and $50 \mathrm{~nm}$ inner diameter (Figure 4). ${ }^{109}$ These nanotubes have been reported to exhibit blue photoluminescence, attributable to quantum confinement within the crystalline structure of the nanotubes, and it has been suggested that this property can be harnessed in novel optical devices. ${ }^{110}$ Besides being thermally and chemically stable, ${ }^{111}$ silver ions can diffuse into the nanotubes and be reduced to furnish silver nanowires; ${ }^{107}$ after proteolytic degradation, the silver nanowires can be isolated and utilized. These three properties render diphenylalanine nanotubes extremely useful for the fabrication of nanowires for manipulation of cells with magnetic force, ${ }^{112}$ biosensing, ${ }^{113}$ as well as electrical stimulation of cells, ${ }^{114}$ among other hitherto unexplored biological applications. That, phenylalanyl-tryptophan has been calculated to possess a higher conductance than diphenylalanine, ${ }^{115}$ suggests that variants with other functional groups can open up even more avenues of bioelectrical applications.

\section{Immunogenicity as a primary challenge for therapeutic peptides}

While the specific antigenicity of the unassembled peptide can be manipulated through the customization of epitopic sequences, the biocompatibility of these peptides might be hindered by the body's potentially heightened immunogenic response to the self-assembled nanostructures of the peptide. ${ }^{116}$ This is especially challenging to address given
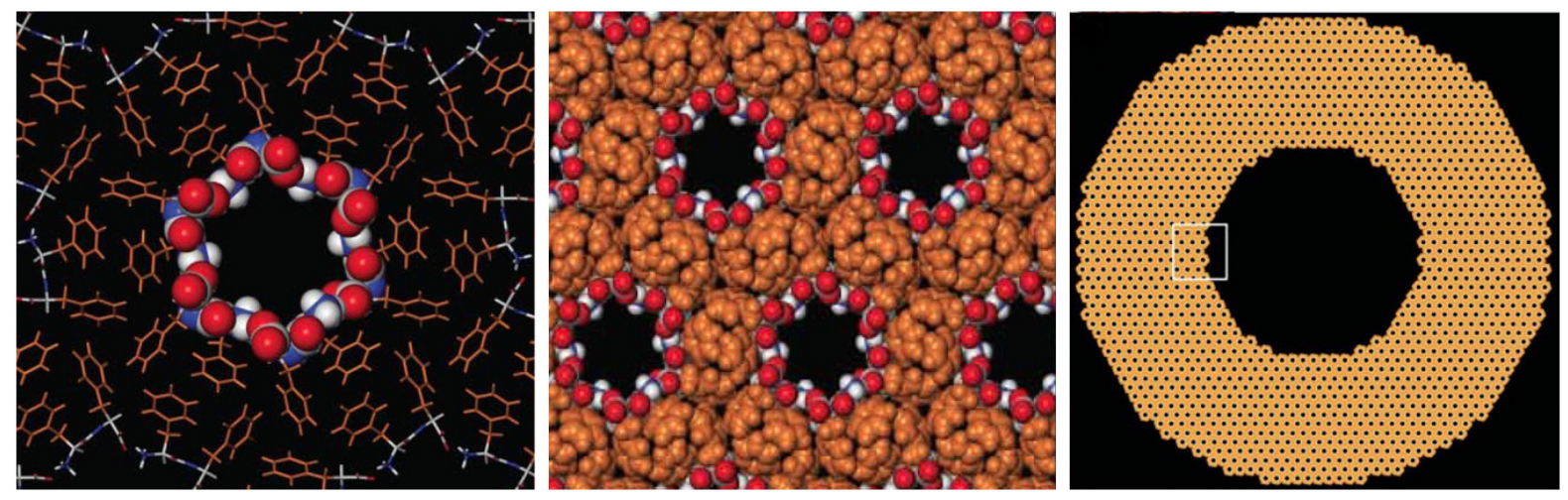

Figure 4 Illustration of how diphenylalanine progressively self-assemble to form a nanotube (left), with more nanotubes clustering together (middle) to form a fibril with $110 \mathrm{~nm}$ outer diameter and $50 \mathrm{~nm}$ inner diameter (right).

Notes: The middle panel is an expansion of the white-lined box in the right panel. The image is reprinted from Goerbitz, ${ }^{109}$ with permission from the Royal Society of Chemistry. 
the various immunologic pathways that can give rise to undesirable immune responses. ${ }^{117}$ For instance, peptides that are products of antigen proteolysis can be bound by the major histocompatibility complex (MHC) II molecules present in antigen-presenting cells and trigger an aversive immunologic cascade. ${ }^{118}$ This process, however, is more complex than previously thought - in addition to significant genetic differences in human MHCs, other enzymatic agents are thought to play a role in the regulation of peptide binding. ${ }^{119}$ This becomes an important point of contention in the consideration of these classes of self-assembling peptides for therapeutic applications.

Recent work by Collier et al ${ }^{120,121}$ has identified a fusion peptide Q11 that exhibits nonimmunogenicity in vivo. Q11 normally provides a reliable immunogenic response when used as an adjuvant on an antigenic peptide $\mathrm{OVA}_{323-339^{\circ}}$ Thus, this opens up the possibility of $\mathrm{OVA}_{323-339}-\mathrm{Q} 11$ functioning as an adjuvant in immunotherapy systems. Further collaboration with Jung et al ${ }^{122,123}$ has also elucidated a $\beta$-fibril self-assembling RGDS-Q11 peptide system that exhibits low immunogenicity in C57BL/6 mice, a promising system for the modeling of other therapeutic peptides. Interestingly, Rudra et al ${ }^{124}$ have demonstrated the T-cell dependence of the immunogenic response involving OVA-containing peptide systems, which could provide possible leads in understanding the mechanism of in vivo peptide binding. In addition, Calis et al ${ }^{125}$ have attempted to establish connections between the strength of the immunogenic response and the properties of peptide-MHC I complexes. Through examining the changes in immunogenicity in the presence of key amino acids and determining the extent of T-cell recognition of peptide positions, Calis et al have proposed a comparative model that understandably remains limited in its predictive power with regard to peptide immunogenicity. A deeper understanding of the underlying immunogenic processes vital for the engineering of nonimmunogenic therapeutic peptides is certainly urgently required.

\section{Conclusion}

In this review, we have shown that three distinct peptide nanostructures, namely nanofibrils, nanoparticles, and nanotubes, display different properties and functions by virtue of their different shapes. Nanofibrils have been shown to exhibit great promise in tissue engineering, but thus far, it has been challenging to utilize the hydrogels in a clinical setting. This is because it is still nontrivial to bioengineer many different types of cells to perform their respective functions in a coordinated manner, so the next step is certainly to develop ways to integrate and coordinate the growth of multiple types of cells within the hydrogel, which is required for a properly functioning tissue. Nanoparticles show great promise in drug/vaccine delivery, and a higher throughput method to incorporate drugs/vaccines will certainly deliver on its longawaited promise of targeted therapy. Last but not least, an efficient way to stabilize nanotubes and control their lengths will certainly contribute greatly to assessing their targeted drug delivery and therapeutic (eg, antibacterial and anticancer) potential. It is apparent that the versatility and tunability of peptides' nanostructures and functions will enable these advancements to be realized in the very near future.

\section{Acknowledgments}

SZ thanks the National Key Basic Research Program of China (2015CB352006), the National High Technology Research and Development Program of China (2015AA020508), the National Natural Science Foundation of China (61275006), the Program for Changjiang Scholars and Innovative Research Team in University (IRT_15R10), the Fujian Provincial Youth Top-notch Talent Support Program, and the Natural Science Foundation for Distinguished Young Scholars of Fujian Province (2014J06016).

\section{Disclosure}

The authors report no conflicts of interest in this work.

\section{References}

1. Whitesides GM, Grzybowski B. Self-assembly at all scales. Science. 2002;295(5564):2418-2421.

2. Hecht MH, Das A, Go A, Bradley LH, Wei YN. De novo proteins from designed combinatorial libraries. Protein Sci. 2004;13(7):1711-1723.

3. Xiong HY, Buckwalter BL, Shieh HM, Hecht MH. Periodicity of polar and nonpolar amino acids is the major determinant of secondary structure in self-assembling oligomeric peptides. Proc Natl Acad Sci US A. 1995;92(14):6349.

4. Huang $X$, Peng $X$, Wang $Y$, et al. A reexamination of active and passive tumor targeting by using rod-shaped gold nanocrystals and covalently conjugated peptide ligands. ACS Nano. 2010;4(10):5887-5896.

5. Lee S, Xie J, Chen X. Activatable molecular probes for cancer imaging. Curr Top Med Chem. 2010;10(11):1135-1144.

6. Smith KH, Tejeda-Montes E, Poch M, Mata A. Integrating top-down and self-assembly in the fabrication of peptide and protein-based biomedical materials. Chem Soc Rev. 2011;40(9):4563-4577.

7. Albericio F, Kruger HG. Therapeutic peptides. Future Med Chem. 2012;4(12):1527-1531.

8. Ahrens VM, Bellmann-Sickert K, Beck-Sickinger AG. Peptides and peptide conjugates: therapeutics on the upward path. Future Med Chem. 2012;4(12):1567-1586.

9. Jacobsen AS, Jenssen H. Human cathelicidin LL-37 prevents bacterial biofilm formation. Future Med Chem. 2012;4(12):1587-1599.

10. Roxin A, Zheng G. Flexible or fixed: a comparative review of linear and cyclic cancer-targeting peptides. Future Med Chem. 2012; 4(12):1601-1618.

11. Chen YR, Gan HX, Tong YW. pH-controlled hierarchical selfassembly of peptide amphiphile. Macromolecules. 2015;48(8): 2647-2653. 
12. Ratner BD, Bryant SJ. Biomaterials: where we have been and where we are going. Annu Rev Biomed Eng. 2004;6:41-75.

13. Xiao L, Wang B, Yang G, Gauthier M. Poly(lactic-acid)-based biomaterials: synthesis, modifications and applications. In: Ghista DN, editor. Biomedical Science, Engineering and Technology. Rijeka: InTech; 2012:247.

14. Liu Y, Yin Y, Wang L, et al. Surface hydrophobicity of microparticles modulates adjuvanticity. J Mater Chem B. 2013;1:3888-3896.

15. Wegmuller S, Schmid S. Recombinant peptide production in microbial cells. Curr Organic Chem. 2014;18(8):1005-1019.

16. Bruckdorfer T, Marder O, Albericio F. From production of peptides in milligram amounts for research to multi-tons quantities for drugs of the future. Curr Pharm Biotechnol. 2004;5(1):29-43.

17. Jacobs CR, Huang H, Kwon RY. Introduction to Cell Mechanics and Mechanobiology. New York, NY: Garland Science, Taylor \& Francis Group, LLC; 2013.

18. Murphy WL, McDevitt TC, Engler AJ. Materials as stem cell regulators. Nat Mater. 2014;13(6):547-557.

19. Arslan E, Garip IC, Gulseren G, Tekinay AB, Guler MO. Bioactive supramolecular peptide nanofibers for regenerative medicine. Adv Healthc Mater. 2014;3(9):1357-1376.

20. Amini AR, Laurencin CT, Nukavarapu SP. Bone tissue engineering: recent advances and challenges. Crit Rev Biomed Eng. 2012;40(5):363-408.

21. Mankin HJ, Gebhardt MC, Jennings LC, Springfield DS, Tomford WW. Long-term results of allograft replacement in the management of bone tumors. Clin Orthop Related Res. 1996;324:86-97.

22. Raucci MG, Guarino V, Ambrosio L. Biomimetic strategies for bone repair and regeneration. J Func Biomater. 2012;3(3):688-705.

23. Brookes M, Revell WJ. Blood Supply of Bones. London: SpringerVerlag London; 1998:152.

24. Undale AH, Westendorf JJ, Yaszemski MJ, Khosla S. Mesenchymal stem cells for bone repair and metabolic bone diseases. Mayo Clin Proc. 2009;84(10):893-902.

25. Kristjánsson B, Honsawek S. Current trends of stem cell-based approaches for knee osteoarthritis. OA Tissue Eng. 2013;1:7.

26. Orth P, Rey-Rico A, Venkatesan JK, Madry H, Cucchiarini M. Current perspectives in stem cell research for knee cartilage repair. Stem Cells Cloning. 2014;7:1-17.

27. Mobasheri A, Kalamegam G, Musumeci G, Batt ME. Chondrocyte and mesenchymal stem cell-based therapies for cartilage repair in osteoarthritis and related orthopaedic conditions. Maturitas. 2014;78(3):188-198.

28. Bianco P, Riminucci M, Gronthos S, Robey PG. Bone marrow stromal stem cells: nature, biology, and potential applications. Stem Cells. 2001;19(3):180-192.

29. Li X, Wang L, Fan Y, Feng Q, Cui F-Z, Watari F. Nanostructured scaffolds for bone tissue engineering. J Biomed Mater Res A. 2013; 101(8):2424-2435.

30. Getgood A, Brooks R, Fortier L, Rushton N. Articular cartilage tissue engineering: today's research, tomorrow's practice? J Bone Joint Surg Br. 2009;91(5):565-576.

31. Spiller KL, Maher SA, Lowman AM. Hydrogels for the repair of articular cartilage defects. Tissue Eng B Rev. 2011;17(4):281-299.

32. Chan KH, Zhuo S, Ni M. Priming the surface of orthopedic implants for osteoblast attachment in bone tissue engineering. Int J Med Sci. 2015;12(9):701-707.

33. Matson JB, Zha RH, Stupp SI. Peptide self-assembly for crafting functional biological materials. Curr Opin Solid State Mater Sci. 2011;15(6):225-235.

34. Wozney JM, Seeherman HJ. Protein-based tissue engineering in bone and cartilage repair. Curr Opin Biotechnol. 2004;15(5):392-398.

35. Lee S-H, Shin H. Matrices and scaffolds for delivery of bioactive molecules in bone and cartilage tissue engineering. Adv Drug Deliv Rev. 2007;59(4-5):339-359.

36. Horii A, Wang X, Gelain F, Zhang S. Biological designer self-assembling peptide nanofiber scaffolds significantly enhance osteoblast proliferation, differentiation and 3-D migration. PLoS One. 2007; 2(2):e190
37. Amosi N, Zarzhitsky S, Gilsohn E, et al. Acidic peptide hydrogel scaffolds enhance calcium phosphate mineral turnover into bone tissue. Acta Biomater. 2012;8(7):2466-2475.

38. Hartgerink JD, Beniash E, Stupp SI. Self-assembly and mineralization of peptide-amphiphile nanofibers. Science. 2001;294(5547): 1684-1688.

39. Hartgerink JD, Beniash E, Stupp SI. Peptide-amphiphile nanofibers: a versatile scaffold for the preparation of self-assembling materials. Proc Natl Acad Sci U S A. 2002;99(8):5133-5138.

40. Kisiday J, Jin M, Kurz B, et al. Self-assembling peptide hydrogel fosters chondrocyte extracellular matrix production and cell division: implications for cartilage tissue repair. Proc Natl Acad Sci US A. 2002; 99(15):9996-10001.

41. Kopesky PW, Vanderploeg EJ, Sandy JS, Kurz B, Grodzinsky AJ. Self-assembling peptide hydrogels modulate in vitro chondrogenesis of bovine bone marrow stromal cells. Tissue Eng A. 2010;16(2): 465-477.

42. Miller RE, Grodzinsky AJ, Vanderploeg EJ, et al. Effect of selfassembling peptide, chondrogenic factors, and bone marrow-derived stromal cells on osteochondral repair. Osteoarthritis Cartilage. 2010;18(12):1608-1619.

43. Okamoto T, Yamamoto Y, Gotoh M, et al. Cartilage regeneration using slow release of bone morphogenetic protein-2 from a gelatin sponge to treat experimental canine tracheomalacia: a preliminary report. ASAIO J. 2003;49(1):63-69.

44. Yamamoto Y, Okamoto T, Goto M, Yokomise H, Yamamoto M, Tabata Y. Experimental study of bone morphogenetic proteins-2 slow release from an artificial trachea made of biodegradable materials: evaluation of stenting time. ASAIO J. 2003;49(5):533-536.

45. Igai H, Yamamoto Y, Chang SS, Yamamoto M, Tabata Y, Yokomise H. Tracheal cartilage regeneration by slow release of basic fibroblast growth factor from a gelatin sponge. J Thorac Cardiovasc Surg. 2007; 134(1):170-175.

46. Yaylaci SU, Sen M, Bulut O, Arslan E, Guler MO, Tekinay AB. Chondrogenic differentiation of mesenchymal stem cells on glycosaminoglycan-mimetic peptide nanofibers. ACS Biomater Sci Eng. 2016;2(5):871-878.

47. Shah RN, Shah NA, Lim MMDR, Hsieh C, Nuber G, Stupp SI. Supramolecular design of self-assembling nanofibers for cartilage regeneration. Proc Natl Acad Sci U S A. 2010;107(8):3293.

48. Mwale F, Demers CN, Petit A, et al. A synthetic peptide of link protein stimulates the biosynthesis of collagens II, IX and proteoglycan by cells of the intervertebral disc. J Cell Biochem. 2003;88(6):1202-1213.

49. Petit A, Yao G, Al Rowas S, et al. Effect of synthetic link N peptide on the expression of type I and type II collagens in human intervertebral disc cells. Tissue Eng A. 2011;17(7-8):899-904.

50. Wang B, Wu Y, Shao Z, et al. Functionalized self-assembling peptide nanofiber hydrogel as a scaffold for rabbit nucleus pulposus cells. J Biomed Mater Res A. 2012;100A(3):646-653.

51. Ma K, Wu Y, Wang B, Yang S, Wei Y, Shao Z. Effect of a synthetic link $N$ peptide nanofiber scaffold on the matrix deposition of aggrecan and type II collagen in rabbit notochordal cells. J Mater Sci Mater Med. 2013;24(2):405-415.

52. Wang B, Sun C, Shao Z, et al. Designer self-assembling peptide nanofiber scaffolds containing link protein $\mathrm{N}$-terminal peptide induce chondrogenesis of rabbit bone marrow stem cells. Biomed Res Int. 2014;2014:421954.

53. Wolford LM, Stevao ELL. Considerations in nerve repair. Proc (Bayl Univ Med Cent). 2003;16(2):152.

54. WHO [webpage on the Internet]. Spinal cord injury. Available from: www.who.int/mediacentre/factsheets/fs384/en/. Accessed December 30, 2016.

55. Yiu G, He Z. Glial inhibition of CNS axon regeneration. Nat Rev Neurosci. 2006;7(8):617-627.

56. Gelain F, Bottai D, Vescovi A, Zhang S. Designer self-assembling peptide nanofiber scaffolds for adult mouse neural stem cell 3-dimensional cultures. PLoS One. 2006;1:e119. 
57. D'Souza SE, Ginsberg MH, Plow EF. Arginyl-glycyl-aspartic acid (RGD): a cell adhesion motif. Trends Biochem Sci. 1991;16(7): 246-250.

58. Mehrban N, Zhu B, Tamagnin F, et al. Functionalized $\alpha$-helical peptide hydrogels for neural tissue engineering. ACS Biomat Sci Eng. 2015;1(6): 431-439.

59. Tashiro K-I, Sephel GC, Weeks B, et al. A synthetic peptide containing the IKVAV sequence from the A chain of laminin mediates cell attachment, migration, and neurite outgrowth. J Biol Chem. 1989;264(27): 16174-16182.

60. Cheng T-Y, Chen M-H, Chang W-H, Huang M-Y, Wang T-W. Neural stem cells encapsulated in a functionalized self-assembling peptide hydrogel for brain tissue engineering. Biomaterials. 2013;34(8): 2005-2016.

61. Kaneko A, Matsushita A, Sankai Y. A 3D nanofibrous hydrogel and collagen sponge scaffold promotes locomotor functional recovery, spinal repair, and neuronal regeneration after complete transection of the spinal cord in adult rats. Biomed Mater. 2015;10(1):015008.

62. Bakota EL, Wang Y, Danesh FR, Hartgerink JD. Injectable multidomain peptide nanofiber hydrogel as a delivery agent for stem cell secretome. Biomacromolecules. 2011;12(5):1651-1657.

63. Wickremasinghe NC, Kumar VA, Shi S, Hartgerink JD. Controlled angiogenesis in peptide nanofiber composite hydrogels. ACS Biomater Sci Eng. 2015;1(9):845-854.

64. Galler KM, Hartgerink JD, Cavender AC, Schmalz G, D'souza RN. A customized self-assembling peptide hydrogel for dental pulp tissue engineering. Tissue Eng Part A. 2012;18(1-2):176-184.

65. Liu $X$, Wang $X$, Horii A, et al. In vivo studies on angiogenic activity of two designer self-assembling peptide scaffold hydrogels in the chicken embryo chorioallantoic membrane. Nanoscale. 2012; 4(8):2720-2727.

66. Kumar VA, Taylor NL, Shi S, et al. Highly angiogenic peptide nanofibers. ACS Nano. 2015;9(1):860-868.

67. Adler-Abramovich L, Gazit E. Controlled patterning of peptide nanotubes and nanospheres using inkjet printing technology. J Pept Sci. 2008;14(2):217-223.

68. Slotta UK, Rammensee S, Gorb S, Scheibel T. An engineered spider silk protein forms microspheres. Angew Chem Int Ed Engl. 2008;47(24): 4592-4594.

69. Fan Z, Sun L, Huang Y, Wang Y, Zhang M. Bioinspired fluorescent dipeptide nanoparticles for targeted cancer cell imaging and real-time monitoring of drug release. Nat Nanotechnol. 2016;11(4): 388-394.

70. Handelman A, Lavrov S, Kudryavtsev A, et al. Nonlinear optical bioinspired peptide nanostructures. Adv Optical Mater. 2013;1(11): 875-884

71. de Bruyn Ouboter D, Schuster TB, Mantion A, Meier W. Hierarchical organization of purely peptidic amphiphiles into peptide beads. $J$ Phys Chem C. 2011;115(30):14583-14590.

72. de Bruyn Ouboter D, Schuster T, Shanker V, Heim M, Meier W. Multicompartment micelle-structured peptide nanoparticles: a new biocompatible gene- and drug-delivery tool. J Biomed Mater Res A. 2014;102(4):1155.

73. Brasseur R, Killian JA, Dekruijff B, Ruysschaert JM. Conformational analysis of gramicidin-gramicidin interactions at the air/water interface suggests that gramicidin aggregates into tube-like structures similar as found in the gramicidin-induced hexagonal HII phase. Biochim Biophysica Acta. 1987;903(1):11-17.

74. Macdonald PM, Seelig J. Dynamic properties of gramicidin A in phospholipid membranes. Biochemistry. 1988;27(7):2357-2364.

75. Krebs MRH, Devlin GL, Donald AM. Protein particulates: another generic form of protein aggregation? Biophys J. 2007;92(4): 1336-1342.

76. Nigen M, Gaillard C, Croguennec T, Madec M-N, Bouhallab S. Dynamic and supramolecular organisation of alpha-lactalbumin/ lysozyme microspheres: a microscopic study. Biophys Chem. 2010; 146(1):30-35.
77. Kogan MJ, Olmedo I, Hosta L, Guerrero AR, Cruz LJ, Albericio F. Peptides and metallic nanoparticles for biomedical applications. Nanomedicine. 2007;2(3):287-306.

78. Crombez L, Morris MC, Deshayes S, Heitz F, Divita G. Peptide-based nanoparticle for ex vivo and in vivo drug delivery. Curr Pharm Design. 2008;14(34):3656-3665.

79. Pearce TR, Shroff K, Kokkoli E. Peptide targeted lipid nanoparticles for anticancer drug delivery. Adv Mater. 2012;24(28):3803-3822.

80. Oltra NS, Nair P, Discher DE. From stealthy polymersomes and filomicelles to "self" Peptide-nanoparticles for cancer therapy. Ann Rev Chem Biomol Eng. 2014;5:281-299.

81. Li N, Li N, Yi Q, et al. Amphiphilic peptide dendritic copolymerdoxorubicin nanoscale conjugate self-assembled to enzyme-responsive anti-cancer agent. Biomaterials. 2014;35(35):9529-9545.

82. Raman S, Machaidze G, Lustig A, Aebi U, Burkhard P. Structurebased design of peptides that self-assemble into regular polyhedral nanoparticles. Nanomedicine. 2006;2(2):95-102.

83. Wahome N, Pfeiffer T, Ambiel I, et al. Conformation-specific display of 4E10 and 2F5 epitopes on self-assembling protein nanoparticles as a potential HIV vaccine. Chem Biol Drug Design. 2012; 80(3):349-357.

84. Babapoor S, Neef T, Mittelholzer C, et al. A novel vaccine using nanoparticle platform to present immunogenic M2e against avian influenza infection. Influenza Res Treat. 2011;2011:126794.

85. Kaba SA, Brando C, Guo Q, et al. A nonadjuvanted polypeptide nanoparticle vaccine confers long-lasting protection against rodent malaria. J Immunol. 2009;183(11):7268-7277.

86. Burkhard P, Lanar DE. Malaria vaccine based on self-assembling protein nanoparticles. Expert Rev Vaccines. 2015;14(12):1525-1527.

87. Kim H, Park HT, Tae YM, et al. Bioimaging and pulmonary applications of self-assembled Flt1 peptide-hyaluronic acid conjugate nanoparticles. Biomaterials. 2013;34(33):8478-8490.

88. Beack S, Choi JS, Lee JH, et al. Two-photon microscopy of a Flt1 peptidehyaluronate conjugate. Nanomedicine (Lond). 2015;10(15):2315-2324

89. Valery C, Artzner F, Paternostre M. Peptide nanotubes: molecular organisations, self-assembly mechanisms and applications. Soft Matter. 2011;7:9583-9594.

90. Hamley IW. Peptide nanotubes. Angew Chem Int Ed Engl. 2014; 53(27):6866-6881.

91. Oakley MT, Johnston RL. Energy landscapes and global optimization of self-assembling cyclic peptides. JChem Theory Comput. 2014;10(4): 1810-1816.

92. Ghadiri MR, Granja JR, Milligan RA, McRee DE, Khazanovich N. Self-assembling organic nanotubes based on a cyclic peptide architecture. Nature. 1993;366(6453):324-327.

93. Chapman R, Danial M, Koh ML, Jolliffe KA, Perrier S. Design and properties of functional nanotubes from the self-assembly of cyclic peptide templates. Chem Soc Rev. 2012;41(18):6023-6041.

94. Verkman AS. Aquaporins in clinical medicine. Ann Rev Med. 2012;63:303-316.

95. Scanlon S, Aggeli A. Self-assembling peptide nanotubes. Nano Today. 2008;3(3-4):22-30.

96. Adler-Abramovich L, Gazit E. Self-assembled peptide nanostructures. In: Sattler KD, editor. Handbook of Nanophysics. Boca Raton, FL: CRC Press; 2010.

97. Brea RJ, Reiriz C, Granja JR. Towards functional bionanomaterials based on self-assembling cyclic peptide nanotubes. Chem Soc Rev. 2010;39(5):1448-1456.

98. Montenegro J, Ghadiri MR, Granja JR. Ion channel models based on self-assembling cyclic peptide nanotubes. Acc Chem Res. 2013;46(12): 2955-2965.

99. Rodriguez-Vazquez N, Ozores HL, Guerra A, et al. Membrane-targeted self-assembling cyclic peptide nanotubes. Curr Top Med Chem. 2014; 14:2647-2661.

100. Garcia-Fandino R, Amorin M, Castedo L, Granja JR. Transmembrane ion transport by self-assembling $\alpha, \gamma$-peptide nanotubes. Chem Sci. 2012;3: 3280-3285. 
101. Sun LM, Fan Z, Wang YZ, Huang YJ, Schmidt M, Zhang MJ. Tunable synthesis of self-assembled cyclic peptide nanotubes and nanoparticles. Soft Matter. 2015;11(19):3822-3832.

102. Hourani R, Zhang C, van der Weegen R, et al. Processable cyclic peptide nanotubes with tunable interiors. J Am Chem Soc. 2011;133(39): 15296-15299.

103. Ruiz L, Wu Y, Keten S. Tailoring the water structure and transport in nanotubes with tunable interiors. Nanoscale. 2015;7(1):121-132.

104. Vrignaud S, Benoit J-P, Saulnier P. Strategies for the nanoencapsulation of hydrophilic molecules in polymer-based nanoparticles. Biomaterials. 2011;32(33):8593-8604.

105. Montenegro J, Vazquez-Vazquez C, Kalinin A, Geckeler KE, Granja JR. Coupling of carbon and peptide nanotubes. J Am Chem Soc. 2014;136(6):2484.

106. Zhang $\mathrm{C}, \mathrm{Xu} \mathrm{T}$. Co-assembly of cyclic peptide nanotubes and block copolymers in thin films: controlling the kinetic pathway. Nanoscale. 2015;7(37):15117-15121.

107. Reches M, Gazit E. Casting metal nanowires within discrete selfassembled peptide nanotubes. Science. 2003;300(5619):625-627.

108. Adler-Abramovich L, Aronov D, Beker P, et al. Self-assembled arrays of peptide nanotubes by vapour deposition. Nat Nanotechnol. 2009;4(12):849-854

109. Goerbitz $\mathrm{CH}$. The structure of nanotubes formed by diphenylalanine, the core recognition motif of Alzheimer's beta-amyloid polypeptide. Chem Commun (Camb). 2006;(22):2332-2334.

110. Amdursky N, Molotskii M, Aronov D, Adler-Abramovich L, Gazit E, Rosenman G. Blue luminescence based on quantum confinement at peptide nanotubes. Nano Lett. 2009;9(9):3111-3115.

111. Adler-Abramovich L, Reches M, Sedman VL, Allen S, Tendler SJB, Gazit E. Thermal and chemical stability of diphenylalanine peptide nanotubes: implications for nanotechnological applications. Langmuir. 2006;22(3):1313-1320.

112. Reich DH, Tanase M, Hultgren A, Bauer LA, Chen CS, Meyer GJ. Biological applications of multifunctional magnetic nanowires (invited). J Appl Phys. 2003;93:7275.
113. Adolfsson K, Persson H, Wallentin J, et al. Fluorescent nanowire heterostructures as a versatile tool for biology applications. Nano Lett. 2013; 13(10):4728-4732.

114. Kang M, Lee H, Kang T, Kim B. Synthesis, properties, and biological application of perfect crystal gold nanowires: a review. J Mater Sci Technol. 2015;31(6):573-580.

115. Akdim B, Pachter R, Naik RR. Self-assembled peptide nanotubes as electronic materials: An evaluation from first-principles calculations. Appl Phys Lett. 2015;106(18):183707.

116. Van Regenmortel MHV. Antigenicity and immunogenicity of synthetic peptides. Biologicals. 2001;29(3-4):209-213.

117. Medzhitov R. Recognition of microorganisms and activation of the immune response. Nature. 2007;449(7164):819-826.

118. Purcell AW, McCluskey J, Rossjohn J. More than one reason to rethink the use of peptides in vaccine design. Nat Rev Drug Discov. 2007;6(5):404-414.

119. Flower DR. Designing immunogenic peptides. Nat Chem Biol. 2013;9(12):748-753.

120. Rudra JS, Tian YF, Jung JP, Collier JH. A self-assembling peptide acting as an immune adjuvant. Proc Natl Acad Sci U S A. 2010; 107(2):622-627.

121. Rudra JS, Mishra S, Chong AS, et al. Self-assembled peptide nanofibers raising durable antibody responses against a malaria epitope. Biomaterials. 2012;33(27):6476-6484.

122. Jung JP, Nagaraj AK, Fox EK, Rudra JS, Devgun JM, Collier JH. Co-assembling peptides as defined matrices for endothelial cells. Biomaterials. 2009;30(12):2400-2410.

123. Jung JP, Gasiorowski JZ, Collier JH. Fibrillar peptide gels in biotechnology and biomedicine. Biopolymers. 2010;94(1):49-59.

124. Rudra JS, Sun T, Bird KC, et al. Modulating adaptive immune responses to peptide self-assemblies. ACS Nano. 2012;6(2):1557-1564.

125. Calis JJA, Maybeno M, Greenbaum JA, et al. Properties of MHC class I presented peptides that enhance immunogenicity. PLoS Comput Biol. 2013;9(10):e1003266.
International Journal of Nanomedicine

\section{Publish your work in this journal}

The International Journal of Nanomedicine is an international, peerreviewed journal focusing on the application of nanotechnology in diagnostics, therapeutics, and drug delivery systems throughout the biomedical field. This journal is indexed on PubMed Central, MedLine, CAS, SciSearch $®$, Current Contents ${ }^{\circledR} /$ Clinical Medicine,

\section{Dovepress}

Journal Citation Reports/Science Edition, EMBase, Scopus and the Elsevier Bibliographic databases. The manuscript management system is completely online and includes a very quick and fair peer-review system, which is all easy to use. Visit http://www.dovepress.com/ testimonials.php to read real quotes from published authors. 